\title{
Impact of multimodal interventions on medication nonadherence among elderly hypertensives: a randomized controlled study
}

This article was published in the following Dove Press journal: Patient Preference and Adherence

\author{
Melita Sheilini (D)' \\ H Manjunatha Hande ${ }^{2}$ \\ Mukhyaprana M Prabhu $\mathbb{D}^{2}$ \\ Mamatha Shivananda Pai $\mathbb{D D}^{3}$ \\ Anice George 4 \\ 'Department of Medical Surgical Nursing, \\ Manipal College of Nursing Manipal, \\ MAHE, Manipal, Udupi District, \\ Karnataka, India; ${ }^{2}$ Department of \\ Medicine, Kasturba Hospital, MAHE, \\ Manipal, Udupi District, Karnataka, India; \\ ${ }^{3}$ Department of Child Health Nursing, \\ Manipal College of Nursing Manipal, \\ MAHE, Manipal, Udupi District, \\ Karnataka, India; ${ }^{4}$ Department of Child \\ Health Nursing, Manipal College of \\ Nursing Manipal, Manipal MAHE, Manipal, \\ Udupi District, Karnataka, India
}

Correspondence: Melita Sheilini Department of Medical Surgical Nursing, Manipal College of Nursing Manipal, MAHE, Manipal, Udupi District, Karnataka 576104, India

$\mathrm{Tel}+9 \mid 8095976561$

Fax +91 8202922572

Email shyli.mel@manipal.edu
Purpose: The study was conducted to investigate the effects of multimodal interventions on medication nonadherence, quality of life (QoL), hypertension (HTN), self-efficacy, and clinical outcome in terms of blood pressure (BP) among elderly people with HTN.

Methods: An experimental design using a randomized controlled trial was adopted $(\mathrm{N}=80+80)$. The experimental group received multimodal interventions and the control group received routine care. Both groups were followed up at baseline and at 3 and 6 months. The data collection tools of demographic and clinical proforma, structured knowledge questionnaire on HTN $(r=0.84)$, Revised Medication Adherence Self-Efficacy Scale $(r=0.94)$, Morisky Medication Adherence Scale $(r=0.83)$, World Health Organization Quality of Life-BREF scale $(r=0.87)$, and digital BP apparatus were used. Necessary administrative permission was obtained for the study.

Results: The study results proved that nurse-led multimodal interventions led to an improvement in medication adherence $[F(1.75,214.30)=774.18, p<0.001]$, knowledge on HTN $[F(2,244)=43.83, p<0.001]$, and self-efficacy $[F(1,122)=3.99, p=0.04]$ of elderly people on antihypertensives over a period of 6 months. Overall QoL did not exhibit any statistically significant improvement, and no statistically significant reductions in the systolic BP (SBP) and diastolic BP (DBP) scores were obtained $(p>0.05)$ in the experimental group over a period of 6 months. However, the clinical significance of multimodal interventions for improvements in medication adherence, QoL, knowledge on HTN, and self-efficacy was more favorable compared with the reduction in SBP and DBP scores.

Conclusion: Nurses play a crucial role in improving medication adherence among elderly people with HTN.

Trial details: Ethical clearance was obtained (IEC no. KH IEC 253/2012) from the Institutional Ethical Committee of Manipal University, Manipal, and the study was conducted in accordance with the Declaration of Helsinki. The study is registered under Clinical Trials Registry of India (CTRI/2017/04/008405). Informed consent was obtained from participants, and the confidentiality of information was assured.

Keywords: hypertension, elderly, medication adherence, knowledge, self-efficacy, quality of life

\section{Introduction}

Hypertension (HTN) is one of the common preventable noncommunicable diseases. Only $53-70 \%$ of individuals with HTN are estimated to be taking the medication as advised by their physicians. ${ }^{1}$ In 2008 , an estimated 17.3 million people died from cardiovascular diseases, representing $30 \%$ of all global deaths. By 2020, an 11\% rise in deaths due to cardiovascular diseases has been estimated in India, for which 
HTN is one of the major contributing factors. ${ }^{2}$ As per the World Health Organization report of World Hypertension Day 2017, it was estimated at the global level that of the people with HTN, only $57 \%$ are aware of their condition, $40.6 \%$ receive antihypertensive drug treatment, and only $13.2 \%$ achieve controlled blood pressure (BP). ${ }^{3}$ Because patients remain unaware that they have HTN until they develop complications, effective detection and treatment of HTN is vital to reduce the incidence of cardiovascular disease. As one of the frontline care providers in the hospital, nurses play a major role in addressing medication nonadherence.

Studies have extensively assessed nonadherence among people with HTN. However, few studies have been conducted in India to assess the level of adherence to antihypertensives among the elderly people with HTN. Further, no studies have been conducted in the past 10 years using nurse-led interventions to improve the adherence to antihypertensives among elderly people. The present study evaluated the effects of multimodal interventions on medication nonadherence, quality of life (QoL), knowledge on HTN, self-efficacy, and clinical outcome among the elderly people with HTN.

\section{Materials and methods}

\section{Sample and sampling technique}

An experimental design using a randomized controlled trial (RCT) was adopted for the study. The sample comprised a total of 160 nonadherent patients with HTN. Stratified block randomization with a proportionate sampling technique was used for allocating participants to the control $(\mathrm{N}=80)$ and experimental $(\mathrm{N}=80)$ groups. The participants were recruited from the outpatient department of a tertiary care hospital. The experimental group received multimodal interventions and the control group received routine care.

\section{Multimodal intervention}

This included the following components:

- individualized teaching on medication adherence and healthy lifestyle practices;

- information leaflet on medication adherence and healthy lifestyle practices;

- weekly medication-reminder boxes; and

- telephonic reminder for follow-up.

\section{Tools used in the study}

The background information of the participants was collected using the demographic and clinical proforma.

Medication adherence was assessed using the Morisky Medication Adherence Scale (MMAS-8) $\quad(r=0.83)$, a standardized scale authorized for use with due norms. The MMAS- 8 comprises 8 items that focus on the drug taking behavior of the individual. MMAS- 8 scores range from 0 to 8 and have been trichotomized into three adherence levels to facilitate use in clinical practice, namely high adherence (a score of 8 ), medium adherence (a score of $\geq 6$ to $<8$ ), and low adherence (a score of $<6$ ). ${ }^{4}$

Self-efficacy was assessed using the standardized Revised Medication Adherence Self-Efficacy Scale (MASES-R) developed by Fernandez et al in 2008. ${ }^{5}$ The scale comprises 13 items, and each item is scored from 1 (not at all sure) to 4 (extremely sure). The total score ranged between 13 and 39, and the self-efficacy levels were interpreted through a continuous approach based on the scores rather than the categorization of the scores. ${ }^{5}$

QoL was assessed using the standardized World Health Organization Quality of Life-BREF (WHOQOL-BREF) $(r=0.87)$ scale. $^{6}$ The tool comprises 26 items under the physical, psychological, social relationships, and environmental domains. QoL was interpreted based on the scores (ie, higher the scores, higher the QoL).

Knowledge of HTN was assessed using a structured knowledge questionnaire on HTN, comprising 20 items with a maximum score of 20 , with scores ranging from 0-6 (poor knowledge), 7-13 (average knowledge), to 14-20 (good knowledge).

The standardized Kannada versions of the MMAS- 8 and WHOQOL-BREF were obtained with permission from the original author. The other tools were translated into Kannada, and the validation and reliability of the structured knowledge questionnaire on HTN $(r=0.84)$ and MASES-R $(r=0.94)$ were established in Indian settings before the questionnaire was administered to the study participants. The OMRON Digital NIBP analyzer (Model No-Simcube SC-5, Serial No-5459, PRONK Technologies, Muko, Kyoto, Japan) was used for obtaining BP readings.

\section{Ethical considerations}

Ethical clearance was obtained (IEC no. KH IEC 253/ 2012) from the Institutional Ethical Committee of Manipal University, Manipal, and the study was conducted 
in accordance with the Declaration of Helsinki. The study is registered under Clinical Trials Registry of India (CTRI/ 2017/04/008405). Informed consent was obtained from the patients before enrolling them in the study.

\section{Inclusion and exclusion criteria}

Patients aged 60 years and older with stage I and stage II HTN with or without comorbidities such as diabetes mellitus, chronic ischemic heart diseases, dyslipidemias, chronic rheumatism, and any other chronic conditions; those who were able to manage to take medications; and those who were able to read, write, and converse in English/Kannada were included in the study. Patients with renal failure, acute stroke, acute ischemic heart disease, major psychiatric disorders, dementia, or delirium were excluded from the study.

\section{Data collection}

Patient records from the outpatient department were reviewed for identifying patients who met the inclusion criteria. Data were obtained after obtaining written consent from the participants. The patients were surveyed for their medication adherence level using the MMAS-8 scale. The data were collected from July 2013 to February 2017. Comorbidities and sex were the two major variables considered (Figure 1). The participants were blinded to the allocation of groups. The participants were allocated to their groups by casting and drawing lots by the researcher from the respective blocks when the participants arrived at the OPD.

For the intervention, the participants were called individually to a separate room in the OPD and seated comfortably. Thereafter, the BP was measured twice at $1 \mathrm{~min}$ intervals, with the prerequisite that they had not consumed coffee within $1 \mathrm{~h}$ prior to the BP recording. The average of the two BP readings was considered. ${ }^{7}$ Thereafter, the participant was asked to fill the structured knowledge questionnaire on HTN, MASES-R scale, WHOQOL-BREF scale, and perceived family support scale. Subsequently, the participant received teaching on medication adherence, which included a brief introduction to HTN, complications of uncontrolled HTN, dos and don'ts of taking medication, benefits of being adherent, ill-effects of nonadherence, and the necessary lifestyle modifications for the control of BP. An information leaflet covering all of this information, which was prepared in their language of understanding, was also handed to them. After educating the patients, each patient in the experimental group was given weekly medication-reminder boxes and was provided with instructions on how to arrange their medications in the boxes. A telephonic reminder for follow-up and motivation for their drug-taking behavior were provided.

During the second visit in the third month and the third visit in the sixth month, BP was measured again, the adherence level of the patients was assessed using MMAS-8 scale, and the knowledge on HTN, selfefficacy, and QoL were assessed using the structured knowledge questionnaire on HTN, MASES-R scale, and WHOQOL-BREF scale, respectively. During each visit, they were motivated to adhere to their medications.

\section{Results}

The chi-square test and Fischer's exact test were used to determine whether the sample characteristics differed significantly among the groups. The experimental and control groups were comparable in terms of their sociodemographic (Table 1) and clinical variables (Table 2).

Because the data on medication adherence, QoL, and knowledge of HTN did not follow normality, Friedman 2-way ANOVA was performed. Moreover, because of a normal distribution in the data on self-efficacy and clinical outcome, repeated-measures ANOVA was performed to determine the effectiveness of multimodal interventions.

\section{Effect of multimodal interventions on nonadherence to antihypertensives}

A steady improvement in the mean scores of adherence was noted in the experimental group from baseline (5.59) to 3 months (7.93) and 6 months (8.00), whereas in the control group the mean scores at baseline, 3 months and at 6 months were 5.93, 7.60, and 7.70, respectively. Overall, an improvement in the mean scores of adherence was noted in the experimental group compared with the control group. The results of Friedman 2-way ANOVA revealed a significant effect of time (within group) on medication adherence scores among the elderly people on antihypertensives $\quad[F(1.75,214.30)=774.18, \quad p<0.001]$, indicating that the participants in both groups exhibited an improvement in medication adherence over time. Compared with the control group, the improvement in medication adherence was not significant among participants in the experimental group $[F(1,122)=3.31$, $p=0.071]$. The interaction effect (time $\times$ group) was significant $[F(1.75,214.30)=4.24, p=0.020]$, indicating that the group exhibited a change over time, and the change was different across the groups (Table 3 ). 
Target population - elderly patients receiving antihypertensive treatment.

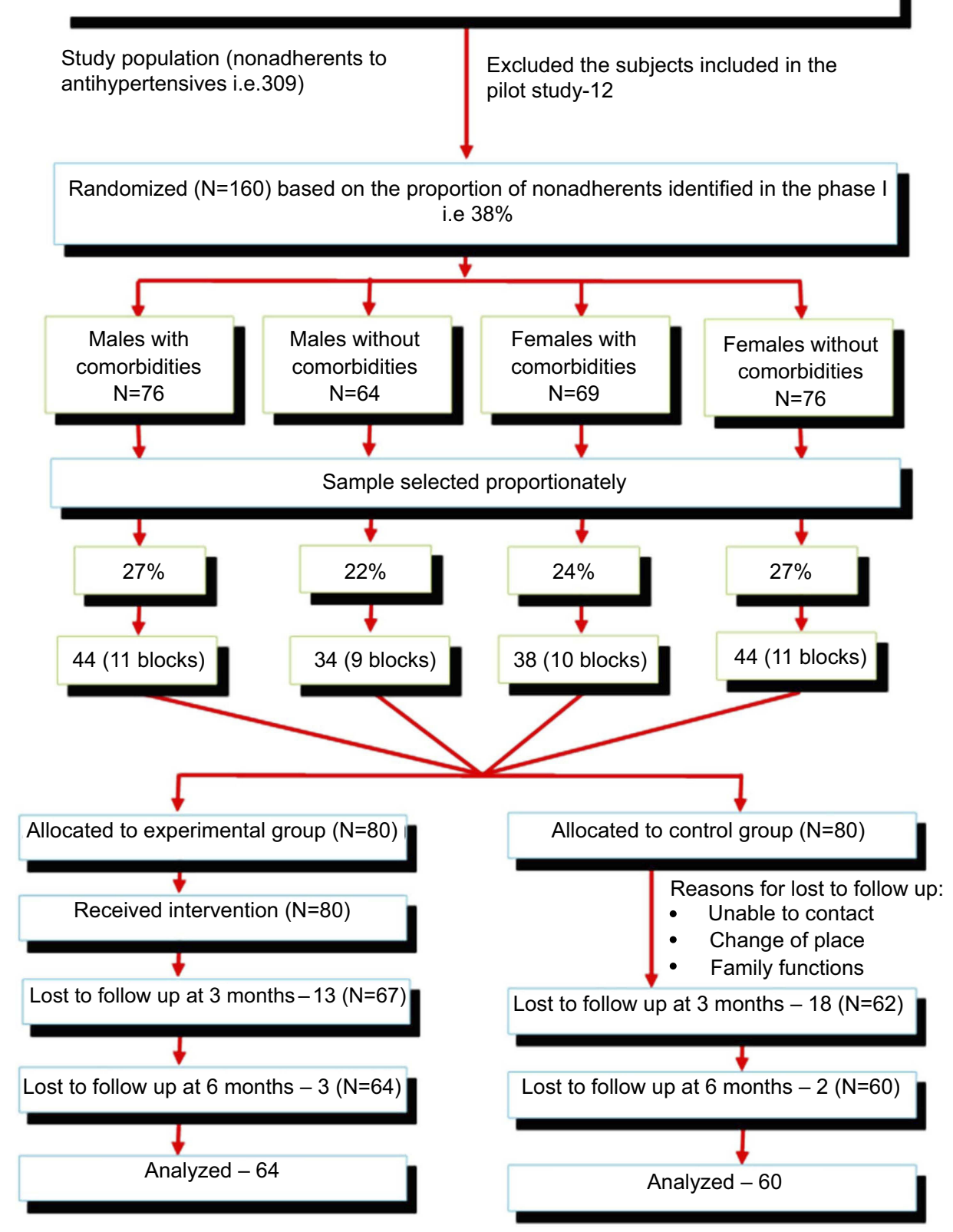

Figure I Consort flow chart of subjects recruited for the study.

\section{Effect of multimodal interventions on QoL}

The baseline mean (SD) QoL scores of the experimental and control groups were 50.54 (11.14) and 50.65 (7.96), respectively. Over a period of 6 months, the experimental group exhibited some improvement in QoL mean scores (50.54-51.85), whereas the control group exhibited improvement from a score of 50.65 to 50.58. The Friedman 2-way ANOVA revealed no significant effect
Excluded the subjects included in the pilot study-12 
Table I. Baseline sociodemographic characteristics of the sample as frequency and percentage $(N=\mid 24)$

\begin{tabular}{|c|c|c|c|c|c|}
\hline \multirow[t]{2}{*}{ Variable } & \multicolumn{2}{|c|}{ Experimental group $(n=64)$} & \multicolumn{2}{|c|}{$\begin{array}{l}\text { Control group } \\
(n=60)\end{array}$} & \multirow[t]{2}{*}{$p$-value } \\
\hline & f & $\%$ & f & $\%$ & \\
\hline Age in years & & & & & 0.662 \\
\hline$\geq 60-70$ & 45 & 42.1 & 40 & 38.8 & \\
\hline$>70$ & 19 & 17.8 & 20 & 19.4 & \\
\hline Gender & & & & & 0.214 \\
\hline Male & 27 & 42.2 & 32 & 53.3 & \\
\hline Female & 37 & 57.8 & 28 & 46.7 & \\
\hline Education & & & & & 0.533 \\
\hline Illiterate & 10 & 9.3 & II & 10.7 & \\
\hline$\leq 7$ th standard & 16 & 15 & 16 & 15.5 & \\
\hline >7th standard-PUC & 30 & 28 & 30 & 29.1 & \\
\hline Degree & 8 & 7.5 & 3 & 2.9 & \\
\hline Occupation & & & & & 0.197 \\
\hline Professional & 5 & 4.7 & 4 & 3.9 & \\
\hline Nonprofessional & 6 & 5.6 & 9 & 8.7 & \\
\hline Business & 2 & 1.9 & 7 & 6.8 & \\
\hline Retired & 12 & 11.2 & 5 & 4.9 & \\
\hline Cooli & 13 & 12.1 & 8 & 7.8 & \\
\hline Not working & 26 & 24.3 & 27 & 26.2 & \\
\hline Living with spouse & & & & & 0.887 \\
\hline Yes & 56 & 52.3 & 53 & 51.5 & \\
\hline No & 8 & 7.5 & 7 & 6.8 & \\
\hline $\begin{array}{l}\text { Annual income of } \\
\text { the family }\end{array}$ & & & & & 0.938 \\
\hline$<12,000$ & 34 & 31.8 & 34 & 33 & \\
\hline I2,000-I lakh & 20 & 18.7 & 18 & 17.5 & \\
\hline$>1-2.5$ lakhs & 5 & 4.7 & 5 & 4.9 & \\
\hline$>2.5$ lakh & 5 & 4.7 & 3 & 2.9 & \\
\hline $\begin{array}{l}\text { Finance for the } \\
\text { treatment }\end{array}$ & & & & & 0.413 \\
\hline Children & 29 & 27.1 & 32 & 31.1 & \\
\hline Own & 25 & 23.4 & 23 & 22.3 & \\
\hline Spouse & 10 & 9.3 & 5 & 4.9 & \\
\hline
\end{tabular}

Note: $\mathrm{N}=124, p<0.05$.

Abbreviation: PUC, Pre University College.

domains of QoL among participants in the experimental group (Table 4).

\section{Effect of multimodal interventions on knowledge on HTN}

Knowledge on HTN improved in the experimental group, with mean scores of 9.68, 10.35, and 11.96 at baseline, 3 months, and 6 months. However, in the control group, the mean scores at baseline, 3 months, and 6 months were $8.21,8.15$, and 9.71, respectively. Overall, improvement in the mean scores of knowledge on HTN was observed in the experimental group compared with the control group. The results of the Friedman 2-way ANOVA revealed a significant effect of time (within group) on knowledge on HTN scores among the elderly people on antihypertensives $[F(2,244)=43.83, p<0.001]$, indicating that the participants in both groups exhibited an improvement in 
Table 2. Baseline clinical characteristics of the sample as frequency and percentage $(N=124)$

\begin{tabular}{|c|c|c|c|c|c|}
\hline \multirow[t]{2}{*}{ Variable } & \multicolumn{2}{|c|}{ Experimental group $(n=64)$} & \multicolumn{2}{|c|}{$\begin{array}{l}\text { Control group } \\
(n=60)\end{array}$} & \multirow[t]{2}{*}{$p$-value } \\
\hline & f & $\%$ & f & $\%$ & \\
\hline Duration of treatment & & & & & 0.864 \\
\hline$<6$ months & 13 & 12.1 & II & 10.7 & \\
\hline $6-12$ months & 1 & 0.9 & 2 & 1.9 & \\
\hline$>1$ year & 50 & 46.7 & 47 & 45.6 & \\
\hline Body mass index $\left(\mathrm{kg} / \mathrm{m}^{2}\right)$ & & & & & 0.170 \\
\hline Underweight $(<18.5)$ & 3 & 2.8 & 4 & 3.9 & \\
\hline Normal (I8.5-24.9) & 42 & 39.3 & 28 & 27.2 & \\
\hline Overweight (25-29.9) & 18 & 16.8 & 25 & 14.3 & \\
\hline Obese $(>30)$ & 1 & 9 & 3 & 2.9 & \\
\hline Comorbidities & & & & & 0.113 \\
\hline Diabetes mellitus & 26 & 24.3 & 39 & 37.9 & \\
\hline Chronic ischemic heart disease & 9 & 8.4 & 3 & 2.9 & \\
\hline Dyslipidemia & 1 & 0.9 & 0 & 0 & \\
\hline Chronic rheumatism & 0 & 0 & 0 & 0 & \\
\hline No comorbidities & 28 & 26.2 & 18 & 17.5 & \\
\hline More than one comorbidity & 0 & 0 & 0 & 0 & \\
\hline Number of medications & & & & & 0.681 \\
\hline $\mathrm{I}-4$ & 44 & 68.7 & 44 & 73.3 & \\
\hline $5-8$ & 18 & 28.1 & 15 & 25 & \\
\hline $9-12$ & 2 & 3.1 & I & 1.6 & \\
\hline Class of antihypertensives & & & & & 0.742 \\
\hline ACE inhibitors & 13 & 20.3 & 14 & 23.3 & \\
\hline Angiotensin II antagonists & 6 & 9.3 & 6 & 10 & \\
\hline ACE inhibitors + diuretics & 2 & 3.1 & 2 & 3.3 & \\
\hline Beta blockers & 12 & 18.7 & 8 & 13.3 & \\
\hline Angiotensin II antagonists + calcium antagonists & 9 & 14.1 & 8 & 1.6 & \\
\hline Beta blockers + ACE inhibitors & 1 & 1.5 & 1 & & \\
\hline Beta blockers + calcium antagonists & 14 & 21.8 & 8 & 13.3 & \\
\hline Calcium antagonists & 7 & 10.9 & 13 & 21.6 & \\
\hline
\end{tabular}

Note: $p<0.05$.

Abbreviation: ACE, angiotensin converting enzyme.

knowledge on HTN over time. Compared with the control group, significant improvement in knowledge on HTN was noted among participants in the experimental group $[F(1,122)=1.91, p<0.001]$. The interaction effect (time $\times-$ group) was also significant $[F(2,244)=6.674, p=0.002]$, indicating that the group exhibited a change over time, and the change was different across the groups (Table 5).

\section{Effect of multimodal interventions on self-efficacy}

Self-efficacy improved in the experimental group, with mean scores of $37.25,37.28$, and 37.37 at baseline,
3 months, and 6 months, respectively. However, in the control group, a reduction in the mean scores of selfefficacy was noted compared with baseline (a shift from 38.03 at baseline to 37.83 at 6 months). Overall, improvement in the mean scores of self-efficacy was noted in the experimental group compared with the control group. The results of repeated-measures ANOVA showed no significant effect of time (within group) on self-efficacy scores among the elderly people on antihypertensives $[F(2,244)$ $=0.73, p=0.48$ ], indicating that participants in both groups exhibited no improvement in self-efficacy over time. Compared with the control group, significant improvement in self-efficacy was noted among participants in the 
Table 3. Friedman 2-way ANOVA on effectiveness of the multimodal intervention on nonadherence of the elderly on antihypertensives $(\mathrm{N}=124)$

\begin{tabular}{|c|c|c|c|c|c|c|c|c|c|}
\hline \multirow[t]{2}{*}{ Variable } & Group & Baseline & $\begin{array}{l}\text { At } 3 \\
\text { months }\end{array}$ & $\begin{array}{l}\text { At } 6 \\
\text { months }\end{array}$ & & \multirow[t]{2}{*}{$\boldsymbol{F}$} & \multirow[t]{2}{*}{$d f$} & \multirow[t]{2}{*}{$p$-value } & \multirow[t]{2}{*}{$\eta_{p}^{2}$} \\
\hline & & Mean (SD) & Mean (SD) & Mean (SD) & & & & & \\
\hline \multirow[t]{3}{*}{$\begin{array}{l}\text { Medication } \\
\text { adherence }\end{array}$} & $\begin{array}{l}\text { Experimental } \\
(n=64)\end{array}$ & & & & & 774.18 & $1.75,214.30$ & $<0.001$ & 0.86 \\
\hline & Control $(n=60)$ & $5.93(0.44)$ & $7.60(0.86)$ & $7.70(0.72)$ & Group & 3.31 & I, I22 & 0.071 & 0.02 \\
\hline & & & & & $\begin{array}{l}\text { Time } \\
\text { xgroup }\end{array}$ & 4.24 & $1.75,214.30$ & 0.020 & 0.03 \\
\hline
\end{tabular}

Notes: Score range 0-8: low adherence $(<6)$, medium adherence $(6-8)$ and high adherence $(=8)$. Time refers to within group effects, group refers to between group effects, and timexgroup refers to interaction effects. $S D=F-$ ratio. $p<0.05$.

Abbreviations: $\mathrm{df}$, degrees of freedom; $\mathrm{\eta}_{\mathrm{p}}{ }^{2}$, partial eta squared (effect size).

Table 4. Friedman 2-way ANOVA on effectiveness of the multimodal intervention on QOL of the elderly on antihypertensives $(\mathrm{N}=124)$

\begin{tabular}{|c|c|c|c|c|c|c|c|c|c|}
\hline \multirow[t]{2}{*}{ Variable } & \multirow[t]{2}{*}{ Group } & Baseline & $\begin{array}{l}\text { At } 3 \\
\text { months }\end{array}$ & $\begin{array}{l}\text { At } 6 \\
\text { months }\end{array}$ & & \multirow[t]{2}{*}{$\boldsymbol{F}$} & \multirow[t]{2}{*}{$d f$} & \multirow[t]{2}{*}{$p$-value } & \multirow[t]{2}{*}{$\eta_{p}{ }^{2}$} \\
\hline & & Mean (SD) & Mean (SD) & Mean (SD) & & & & & \\
\hline \multirow[t]{3}{*}{ Overall QOL } & Experimental $(n=64)$ & $50.54(11.14)$ & $50.04(9.30)$ & $51.85(8.75)$ & Time & 1.34 & 2,244 & 0.26 & 0.011 \\
\hline & Control $(n=60)$ & $50.65(7.96)$ & $48.75(10.53)$ & $50.58(9.45)$ & Group & 1.06 & 1,122 & 0.30 & 0.009 \\
\hline & & & & & Timexgroup & 0.18 & 2,244 & 0.82 & 0.002 \\
\hline Physical & Experimental $(n=64)$ & $12.64(2.72)$ & $|2.5|(2.13)$ & I3.0| (2.01) & Time & 2.17 & 2,244 & 0.11 & 0.018 \\
\hline \multirow[t]{2}{*}{ domain-QOL } & Control $(n=60)$ & $12.63(2.08)$ & $12.35(2.21)$ & $12.73(2.08)$ & Group & 2.17 & 1,122 & 0.14 & 0.01 \\
\hline & & & & & Timexgroup & 0.01 & 2,244 & 0.98 & $<0.001$ \\
\hline Psychological & Experimental $(n=64)$ & $12.34(2.64)$ & $12.39(2.56)$ & $13.0 \mid(2.10)$ & Time & 2.49 & 2,244 & 0.08 & 0.02 \\
\hline \multirow[t]{2}{*}{ domain-QOL } & Control $(n=60)$ & $12.20(1.97)$ & I2.0| (2.88) & $12.53(2.32)$ & Group & 2.83 & 1,122 & $<0.001$ & $<0.999$ \\
\hline & & & & & Timexgroup & 0.21 & 2,244 & 0.80 & 0.002 \\
\hline Social relation- & Experimental $(n=64)$ & $11.92(4.20)$ & II.7| (3.76) & $12.12(3.69)$ & Time & 0.92 & 2,244 & 0.39 & 0.008 \\
\hline ships domain- & Control $(n=60)$ & $12.20(3.28)$ & $11.18(4.19)$ & $11.80(3.99)$ & Group & 3.64 & 1,122 & $<0.001$ & $<0.999$ \\
\hline QOL & & & & & Timexgroup & 0.18 & 2,244 & 0.83 & 0.002 \\
\hline Environmental & Experimental $(n=64)$ & I 3.64 (2.39) & $13.42(2.15)$ & $13.70(2.06)$ & Time & 0.50 & 2,244 & 0.60 & 0.004 \\
\hline \multirow[t]{2}{*}{ domain-QOL } & Control $(n=60)$ & 13.61 (1.91) & $13.20(2.23)$ & $|3.5|(2.26)$ & Group & 0.68 & 1,122 & $0.4 I$ & 0.006 \\
\hline & & & & & Timexgroup & 0.02 & 2,244 & 0.97 & $<0.001$ \\
\hline
\end{tabular}

Notes: Score range 26-130. A high score represents a better functioning in that particular domain of QoL. Overall QoL is a sum of physical domain, psychological domain, social relationships domain, and environmental domain. Time refers to within group effects, group refers to between group effects, and timexgroup refers to interaction effects. SD=F-ratio. $p<0.05$.

Abbreviations: $\mathrm{df}$, degrees of freedom; $\eta_{\mathrm{p}}{ }^{2}$, partial eta squared (effect size); QoL, quality of life.

experimental group $[F(1,122)=3.99, p=0.04]$. The interaction effect (timex group) was not significant $[F(2.244)$ $=0.72, p=0.48]$, indicating not much variation was observed in the change across the groups (Table 6).

\section{Effect of multimodal interventions on clinical outcome in terms of $\mathrm{BP}$}

The systolic BP (SBP) and diastolic BP (DBP) improved in the experimental group, with mean scores of 154.34 and
86.25 at baseline and 153.28 and 84.96 at 6 months, respectively. However, in the control group, the mean scores of SBP and DBP were 154.66 and 85.73 at baseline and 154.83 and 87.30 at 6 months, respectively. Repeated-measures ANOVA showed no significant effect of time (within group) $[F(2,244)$ $=0.29, p=0.74 ; F(2,244)=0.55, p=0.57]$ and group (between groups) $[F(1,122)=1.06, p=0.30 ; F(2,244)=1.94, p=0.16]$ on SBP and DBP scores among the elderly people on antihypertensives. The interaction effect (time $\times$ group) was also not 
Table 5. Friedman 2-way ANOVA on effectiveness of the multimodal intervention on knowledge on HTN of the elderly on antihypertensives $(\mathrm{N}=124)$

\begin{tabular}{|c|c|c|c|c|c|c|c|c|c|}
\hline \multirow[t]{2}{*}{ Variable } & \multirow[t]{2}{*}{ Group } & Baseline & At 3 months & At 6 months & & \multirow[t]{2}{*}{$\boldsymbol{F}$} & \multirow[t]{2}{*}{$d f$} & \multirow[t]{2}{*}{$p$-value } & \multirow[t]{2}{*}{$\eta_{p}^{2}$} \\
\hline & & Mean (SD) & Mean (SD) & Mean (SD) & & & & & \\
\hline \multirow{3}{*}{$\begin{array}{l}\text { Knowledge } \\
\text { on HTN }\end{array}$} & \multirow{3}{*}{$\begin{array}{l}\text { Experimental }(n=64) \\
\text { Control }(n=60)\end{array}$} & 9.68 (3.24) & $10.35(2.72)$ & 11.96 (3.06) & Time & 43.83 & 2,244 & $<0.001$ & 0.26 \\
\hline & & $8.21(1.88)$ & $8.15(1.72)$ & 9.71 (3.2I) & Group & 1.91 & 1,122 & $<0.001$ & 1.00 \\
\hline & & & & & Timexgroup & 6.67 & 2,244 & 0.002 & 0.052 \\
\hline
\end{tabular}

Note: Score range 0-20: poor knowledge (0-6), average knowledge (7-13), and good knowledge (14-20). Time refers to within group effects, group refers to between group effects, and timexgroup refers to interaction effects. $S D=F-$ ratio. $p<0.05$.

Abbreviations: $d f$, degrees of freedom; HTN, hypertension; $\eta_{p}{ }^{2}$, partial eta squared (effect size).

Table 6. Repeated-measures ANOVA on effectiveness of the multimodal intervention on self-efficacy of the elderly on antihypertensives $(\mathrm{N}=124)$

\begin{tabular}{|c|c|c|c|c|c|c|c|c|c|}
\hline \multirow[t]{2}{*}{ Variable } & \multirow[t]{2}{*}{ Group } & \multirow{2}{*}{$\begin{array}{l}\text { Baseline } \\
\text { Mean (SD) }\end{array}$} & \multirow{2}{*}{$\begin{array}{l}\text { At } 3 \text { months } \\
\text { Mean (SD) }\end{array}$} & \multirow{2}{*}{$\begin{array}{l}\text { At } 6 \text { months } \\
\text { Mean (SD) }\end{array}$} & & \multirow[t]{2}{*}{$\boldsymbol{F}$} & \multirow[t]{2}{*}{$d f$} & \multirow[t]{2}{*}{$p$-value } & \multirow[t]{2}{*}{$\eta_{p}{ }^{2}$} \\
\hline & & & & & & & & & \\
\hline \multirow[t]{3}{*}{ Self-efficacy } & Experimental $(n=64)$ & $37.25(2.58)$ & $37.28(2.56)$ & $37.37(2.43)$ & Time & 0.73 & 2,244 & 0.48 & 0.006 \\
\hline & Control $(n=60)$ & $38.03(1.82)$ & $37.30(2.49)$ & $37.83(2.10)$ & Group & 3.99 & 1,122 & 0.04 & 0.032 \\
\hline & & & & & Timexgroup & 0.72 & 2,244 & 0.48 & 0.006 \\
\hline
\end{tabular}

Notes: Score range 13-39. Time refers to within group effects, group refers to between group effects, and timexgroup refers to interaction effects. SD=F-ratio. $p<0.05$. Abbreviations: $d f$, degrees of freedom; $\eta_{p}{ }^{2}$, partial eta squared (effect size).

Table 7. Repeated-measures ANOVA on effectiveness of the multimodal intervention on clinical outcome (BP) of the elderly on antihypertensives $(\mathrm{N}=124)$

\begin{tabular}{|c|c|c|c|c|c|c|c|c|c|}
\hline \multirow[t]{2}{*}{ Variable } & \multirow[t]{2}{*}{ Group } & Baseline & At 3 months & At 6 months & & \multirow[t]{2}{*}{$\boldsymbol{F}$} & \multirow[t]{2}{*}{$d f$} & \multirow[t]{2}{*}{$p$-value } & \multirow[t]{2}{*}{$\eta_{p}{ }^{2}$} \\
\hline & & Mean (SD) & Mean (SD) & Mean (SD) & & & & & \\
\hline Systolic BP & $\begin{array}{l}\text { Experimental }(n=64) \\
\text { Control }(n=60)\end{array}$ & $\begin{array}{l}154.34 \\
(10.34) \\
154.66(11.26)\end{array}$ & $\begin{array}{l}153.96(12.37) \\
156.13(10.59)\end{array}$ & $\begin{array}{l}153.28(12.85) \\
154.83(11.57)\end{array}$ & $\begin{array}{l}\text { Time } \\
\text { Group } \\
\text { Timexgroup }\end{array}$ & $\begin{array}{l}0.29 \\
1.06 \\
0.18\end{array}$ & $\begin{array}{l}2,244 \\
1,122 \\
2,244\end{array}$ & $\begin{array}{l}0.74 \\
0.30 \\
0.83\end{array}$ & $\begin{array}{l}0.002 \\
0.009 \\
0.001\end{array}$ \\
\hline Diastolic BP & $\begin{array}{l}\text { Experimental }(n=64) \\
\text { Control }(n=60)\end{array}$ & $\begin{array}{l}86.28(7.01) \\
85.73(6.58)\end{array}$ & $\begin{array}{l}86.25(6.28) \\
87.43(6.57)\end{array}$ & $\begin{array}{l}84.96(6.89) \\
87.30(7.99)\end{array}$ & $\begin{array}{l}\text { Time } \\
\text { Group } \\
\text { Timexgroup }\end{array}$ & $\begin{array}{l}0.55 \\
1.94 \\
1.31\end{array}$ & $\begin{array}{l}2,244 \\
1,122 \\
2,244\end{array}$ & $\begin{array}{l}0.57 \\
0.16 \\
0.27\end{array}$ & $\begin{array}{l}0.005 \\
0.01 \\
0.011\end{array}$ \\
\hline
\end{tabular}

Notes: Time refers to within group effects, group refers to between group effects, and timexgroup refers to interaction effects. $S D=F-$ ratio. $p<0.05$. Abbreviations: BP, blood pressure; $d f$, degrees of freedom; $\eta_{p}{ }^{2}$, partial eta squared (effect size).

significant $[F(2,244)=0.18, p=0.83 ; F(2,244)=1.31, p=0.27]$, indicating that the SBP and DBP did not change significantly over time (Table 7).

\section{Clinical significance of multimodal interventions}

The clinical use of multimodal interventions was tested using the group-level clinical significance indices [ie, effect size (ES)] and individual-level indices (ie, percentage change). The ES reflects the magnitude of the difference in outcomes between groups. Because repeated-measures
ANOVA was used for data analysis, the corresponding "partial eta squared" $\left(\eta_{\mathrm{p}}{ }^{2}\right)$ was used as a measure of ES. The magnitude of effect, as measured by $\eta_{\mathrm{p}}{ }^{2}$, was interpreted as small $\left(\mathrm{\eta}_{\mathrm{p}}{ }^{2}<0.5\right)$, moderate $\left(\mathrm{\eta}_{\mathrm{p}}{ }^{2}=0.5-0.8\right)$, and large $\left(\mathrm{n}_{\mathrm{p}}{ }^{2}>0.8\right){ }^{23}$ The between-group ES values for SBP $\left(\mathrm{\eta}_{\mathrm{p}}{ }^{2}=0.009\right)$ and DBP $\left(\mathrm{\eta}_{\mathrm{p}}{ }^{2}=0.016\right)$ indicate that the multimodal intervention had a small effect on the clinical outcomes of the elderly people on antihypertensives (Table 7).

The findings also revealed that the participants in the experimental group exhibited greater improvement percentages in medication adherence, overall QoL, physical domain- 
QoL, psychological domain-QoL, social relationships domain-QoL, environmental-QoL, knowledge on HTN, and self-efficacy. The participants in the experimental group exhibited approximately $1 \mathrm{mmHg}$ reduction in SBP and 2 $\mathrm{mmHg}$ reduction in DBP compared to those in the control group. Thus, the clinical significance of multimodal interventions for improvements in medication adherence, QoL, knowledge on HTN, and self-efficacy was more favorable compared with the reduction in SBP and DBP scores (Table 8).

\section{Discussion}

The study findings revealed that multimodal interventions led to an improvement in medication adherence $[F(1.75,214.30)=774.18, \quad p<0.001]$ over a period of 6 months in the experimental group. This is supported by the findings of Stewart et al, ${ }^{8}$ Biradar et al, ${ }^{9}$ Salah et al, ${ }^{1}$ Palanisamy and Sumathy, ${ }^{10}$ Adeyemo et al, ${ }^{11}$ Insel et al, ${ }^{12}$ Aguiar et al, ${ }^{13}$ Ramanath et al, ${ }^{14}$ Moultry et al, ${ }^{15}$ Saleem et al, ${ }^{16}$ Thom et al, ${ }^{17}$ Hedegaard et al, ${ }^{18}$ and Jiang et al, ${ }^{22}$ who also reported an improvement in the adherence to antihypertensive medications over a period of 6 months after adherence counseling/coaching. ${ }^{1,7-1919}$
The present study findings revealed that, compared with the control group, multimodal interventions led to an improvement in knowledge on HTN among participants in the experimental group $[F(1,122)=1.91$, $p<0.001]$ over a period of 6 months. Salah et $\mathrm{al}^{1}$ in Egypt reported highly significant differences between patients' knowledge before and 1, 3, and 6 months after counseling on patients' adherence to antihypertensive therapeutic regimen $(p<0.001)$. In Malaysia, Saleem et al (2013) revealed that after pharmacist intervention, an increase in the mean knowledge score on adherence to antihypertensive therapy $(10.2 \pm 1.1)$ was noted in the intervention group. ${ }^{1515}$

The present study results revealed that although no significant improvement was noted in the overall QoL, significant between-group effects were observed in the psychological domain-QoL and social relationships domain-QoL $(p<0.001)$, indicating that the multimodal intervention was effective in improving the psychological and social relationships domains of QoL of participants in the experimental group.

A study conducted by Ramanath et al (2012) in BG Nagara, Karnataka, showed that patient counseling

Table 8. Percentage change for the outcome variables $(N=124)$

\begin{tabular}{|c|c|c|c|c|c|c|}
\hline Variable & Group & $\mathbf{N}$ & Baseline & Post Test II & Improvement & $\mathbf{P I}$ \\
\hline \multirow[t]{2}{*}{ Medication adherence } & Experimental & 64 & 5.59 & 8.00 & 2.41 & 43.11 \\
\hline & Control & 60 & 5.93 & 7.70 & 1.77 & 29.84 \\
\hline \multirow[t]{2}{*}{ Overall QOL } & Experimental & 64 & 50.54 & 51.85 & 1.31 & 2.59 \\
\hline & Control & 60 & 50.65 & 50.58 & -0.07 & -0.13 \\
\hline \multirow[t]{2}{*}{ Physical domain-QOL } & Experimental & 64 & 12.64 & 13.01 & 0.37 & 2.92 \\
\hline & Control & 60 & 12.63 & 12.73 & 0.1 & 0.79 \\
\hline \multirow[t]{2}{*}{ Psychological domain-QOL } & Experimental & 64 & 12.34 & $13.0 \mid$ & 0.67 & 5.42 \\
\hline & Control & 60 & 12.20 & 12.53 & 0.33 & 2.70 \\
\hline \multirow[t]{2}{*}{ Social relationships domain-QOL } & Experimental & 64 & 11.92 & 12.12 & 0.2 & 1.67 \\
\hline & Control & 60 & 12.20 & 11.80 & -0.4 & -3.27 \\
\hline \multirow[t]{2}{*}{ Environmental domain-QOL } & Experimental & 64 & 13.64 & 13.70 & 0.06 & 0.43 \\
\hline & Control & 60 & $13.6 \mid$ & $|3.5|$ & -0.1 & -0.73 \\
\hline \multirow[t]{2}{*}{ Knowledge on HTN } & Experimental & 64 & 9.68 & 11.96 & 2.28 & 23.55 \\
\hline & Control & 60 & 8.21 & 9.71 & 1.5 & 18.27 \\
\hline \multirow[t]{2}{*}{ Self-efficacy } & Experimental & 64 & 37.25 & 37.37 & 0.12 & 0.32 \\
\hline & Control & 60 & 38.03 & 37.83 & -0.2 & -0.52 \\
\hline Variable & Group & $\mathbf{N}$ & Baseline & Post Test II & Reduction & PR \\
\hline \multirow[t]{2}{*}{ SBP } & Experimental & 64 & 154.34 & 153.28 & 1.06 & 0.68 \\
\hline & Control & 60 & 154.66 & 154.83 & -0.17 & -0.10 \\
\hline \multirow[t]{2}{*}{ DBP } & Experimental & 64 & 86.28 & 84.96 & 1.32 & 1.52 \\
\hline & Control & 60 & 85.73 & 87.30 & -1.57 & -1.83 \\
\hline
\end{tabular}


provided by a clinical pharmacist exerted a positive impact on QoL. ${ }^{1313}$ Moreover, an RCT by Saleem et $\mathrm{al}^{16}$ in Malaysia showed that pharmacist intervention caused a reduction in health related QoL (a shift from 46.7 at baseline to 36.3 after intervention) in the intervention group compared with baseline.

The findings of the present study showed that, compared with the control group, significant improvement in self-efficacy was noted among participants in the experimental group $[F(1,122)=3.99, p=0.04]$. This finding is supported by an RCT by Zhu et $\mathrm{al}^{1919}$ conducted in China, which revealed that after an 8-week nurse-led intervention, a slight increase in the mean score of patient selfefficacy was observed in the study group compared with the control group.

The results of the present study also showed that multimodal interventions did not cause significant reductions in the SBP and DBP scores $(p>0.05)$. Also, the findings of the clinical utility test were not favorable with the reduction in SBP and DBP scores. The BP reduction is very small despite high medication adherence, because the lifestyle practices of the participants were not assessed during follow ups. Also, the impact of lifestyle factors on the clinical outcome in terms of $\mathrm{BP}$ is not assessed and this is one of the major factors which affect the BP readings in spite of high medication adherence. In the US study, Porter et $\mathrm{al}^{20}$ proved that the pill box clinic resulted in clinically significant reductions in SBP by 10 mmHg among people with HTN taking three or more antihypertensives as well as an increased number of patients meeting the prescribed BP goals. An RCT by Stewart et $\mathrm{al}^{8}$ in Australia showed that among the participants with baseline BP above the target levels, the reduction in SBP was significantly greater in the intervention group (by $7.2 \mathrm{mmHg}$ ), indicating that the community pharmacists' intervention was effective in improving BP control. A study by Moultry et $\mathrm{al}^{15}$ conducted at Texas Southern University revealed that at the end of the 6-month intervention period with pharmacist home visits and follow-up educational phone calls, the reduction in mean SBP was significant (baseline, $140 \mathrm{mmHg}$ vs at 6 months, $137 \mathrm{mmHg} ; p<0.049$ ), concluding that the pharmacist-led interventions at home were effective in improving BP control. A study conducted by Aguiar et $\mathrm{al}^{13}$ in Brazil revealed that after a 10-month pharmaceutical care program, $57.2 \%$ of elderly patients achieved BP control and the mean reduction was $26.6 \mathrm{mmHg}$ for SBP and $10.4 \mathrm{mmHg}$ for DBP. In Malaysia, Saleem et $\mathrm{al}^{16}$ also revealed that after pharmacist intervention, lower SBPs and DBPs were observed in the intervention group (7.0 and $5.9 \mathrm{mmHg}$, respectively), thus concluding that pharmacist intervention can significantly increase BP control in patients with HTN. An RCT by Gozum and Hacihasanoglu ${ }^{21}$ conducted in Turkey proved that the nurse-led patient education on medication adherence in combination with teaching on healthy lifestyle behavior was effective in reducing BP among the patients with HTN. Another RCT by Jiang et $\mathrm{al}^{22}$ conducted at tertiary medical centers in Chengdu, southwest China found that a nurse-led cardiac rehabilitation program led to more efficient control of SBP and DBP at 3 months, and the positive effects were sustained at 6 months.

\section{Conclusion}

Adherence to antihypertensives plays a vital role in the management of BP among elderly people and ensures that therapeutic benefits are delivered to the patients. With a steady increase in the elderly population, the burden of noncommunicable diseases will continue to grow, and medication adherence is an urgent requirement because more individuals are placed on long-term prescription regimens. The challenge in India is not only adding further years to life but, more importantly, adding life to years. Increasing the effectiveness of adherence interventions may have a substantially greater impact on the health of the elderly population than an improvement in specific medical treatments.

\section{Abbreviations list}

BP, blood pressure; DBP, diastolic blood pressure; HTN, hypertension; QOL, quality of life; SBP, systolic blood pressure; MMAS-8, Morisky Medication Adherence Scale-8; MASES-R, Revised Medication Adherence Self Efficacy Scale; WHOQOL-BREF, World Health Organization Quality of Life-BREF.

\section{Data sharing statement}

All data generated or analyzed during this study are included in this article.

\section{Data availability}

The patient information leaflet on adherence prepared both in English as well as Kannada is available with the corresponding author. Also, the datasets used and/or analyzed during the current study are available from the corresponding author on reasonable request.

\section{Acknowledgments}

This manuscript was edited by editingindia. This study was self-funded. 


\section{Disclosure}

The authors report no conflicts of interest in this work.

\section{References}

1. Salah M, Ali RES, Talaat A. The effect of counseling on patients' adherence regarding anti hypertensive therapeutic regimen. Life Sci J. 2014;11(5):314-335.

2. Meshram II, Vishnu Vardhana RM, Sudershan RV, Laxmaiah A, Polasa K. Prevalence and correlates of hypertension \& diabetes among $\geq 18$ years urban population in India. Br Biomed Bull. 2015;3(2):176-189.

3. Rouf A, Rasool MSKSM, Haq I, Hamid A, Bashir K, Saleem SM. Prevalence of hypertension and its association with waist circumference in adult population of Block Hazratbal, Srinagar, India. Ann Med Health Sci Res. 2018;8(2):68-73.

4. Morisky DE, Ang A, Krousel-Wood M, Ward H. Predictive validity of a medication adherence measure for hypertension control. $J$ Clin Hypertens. 2008;10(5):348-354. doi:10.1111/j.1751-7176.2008.07572.x

5. Fernandez S, Chaplin W, Schoenthaler AM, Ogedegbe G. Revision and validation of the medication adherence self-efficacy scale (MASES) in hypertensive African Americans. $J$ Behav Med. 2008;31:453-462. doi:10.1007/s10865-008-9170-7

6. Agnihotri K, Awasthi S, Chandra H, Singh U, Thakur S. Validation of WHO QOL-BREF instrument in Indian adolescents. Indian J Paediatr. 2010;77(4):381-386. doi:10.1007/s12098-010-0041-1

7. Smith L. New AHA recommendations for BP measurement. Am Fam Physician. 2005;72(7):1391-1398

8. Stewart K, George J, Mc Namara K, et al. A multifaceted pharmacist intervention to improve antihypertensive adherence: a cluster-randomized, controlled trial (HAPPy trial). J Clin Pharm Ther. 2014;39(5):527-534. doi:10.1111/jcpt.12185

9. Biradar S, Rajashekhar K, Srinivas R, Raju SA. Assessment of pharmacist mediated patient counselling on medication adherence in hypertension patients of South Indian City. Int Res J Pharm. 2012;3 (5):251-255.

10. Palanisamy S, Sumathy A. Intervention to improve patient adherence with antihypertensive medications at a tertiary care teaching hospital. Int J Pharm Tech Res. 2009;1(2):369-374.

11. Adeyemo A, Tayo BO, Luke A, Ogedegbe O, Durazo-Arvizu R, Cooper RS. The Nigerian anti-hypertensive adherence trial (NA-HAT): a community-based randomized trial. $J$ Hypertens. 2013;31(1):201-207. doi:10.1097/HJH.0b013e32835b0842
12. Insel KC, Einstein GO, Morrow DG, Koerner KM, Hepworth JT. Multifaceted prospective memory intervention to improve medication adherence. J Am Geriatr Soc. 2016;64(3):561-568. doi:10.1111/jgs.14032

13. Aguiar PM, Balisa-Rocha BJ, Brito GC, Lyra DP. Pharmaceutical care program forelderly patients with uncontrolled hypertension. $J \mathrm{Am}$ Pharm Assoc. 2012;52(4):515-518. doi:10.1331/japha.2012.11015

14. Ramanath K, Balaji D, Nagakishore C, Kumar SM, Bhanuprakash M. A study on impact of clinical pharmacist interventions on medication adherence and quality of life in rural hypertensive patients. $J$ Young Pharm. 2012;4(2):95-100. doi:10.4103/0975-1483.96623

15. Moultry MA, Pounds K, Poon IO. Managing medication adherence in elderly hypertensive patients through pharmacist home visits. Consult Pharm. 2015;30(12):710-719. doi:10.4140/TCP.n.2015.710

16. Saleem F, Hassali MA, Shafie AA, et al. Pharmacist intervention in improving hypertensionrelated knowledge, treatment medication adherence and health-related quality of life: a non-clinical randomized controlled trial. Heal Expect. 2013;18:1270-1281. doi:10.1111/hex.12101

17. Thom DH, Willard-Grace R, Hessler D, et al. The impact of health coaching on medication adherence in patients with poorly controlled diabetes, hypertension, and/or hyperlipidemia: a randomized controlled trial. J Am Board Fam Med. 2015;28(1):38-45. doi:10.3122/ jabfm.2015.01.140123

18. Hedegaard U, Kieldsen L, Pottegard A, et al. Improving medication adherence in patients with hypertension: a randomized trial. $\mathrm{Am}$ J Med. 2015;128(12):1351-1361. doi:10.1016/j.amjmed.2015.08.011

19. Zhu X, Kam F, Wong Y, Wu LH. Development and evaluation of a nurse-led hypertension management model in a community: a pilot randomized controlled trial. Int J Clin Exp Med. 2014;7(11):4369-4377.

20. Porter AK, Taylor SR, Yabut AH, Al-Achi A. Impact of a pill box clinic to Improve Systolic BP in veterans with uncontrolled hypertension taking 3 or more antihypertensive medications. J Manag Care Spec Pharm. 2014;20(9):905-911. doi:10.18553/jmcp.2014.20.9.905

21. Gozum S, Hacihasanoglu R. The effect of patient education and home monitoring on medication compliance, hypertension management, healthy lifestyle behaviours and BMI in a primary health care setting. J Clin Nurs. 2011;20(5-6):692-705. doi:10.1111/j.13652702.2010.03534.x

22. Jiang X, Wong KT, Sit WJ. Nurse-led cardiac rehabilitation programme improves health behaviours and cardiac physiological risk parameters: evidence from Chengdu,China. $J$ Clin Nurs. 2007;16:1886-1897. doi:10.1111/j.1365-2702.2007.01838.x

23. Cohen J. Statistical Power Analysis for the Behavioural Sciences. 2nd ed. New York: Lawrence Erlbaum Associates Publishers; 1988.
Patient Preference and Adherence

\section{Publish your work in this journal}

Patient Preference and Adherence is an international, peer-reviewed, open access journal that focusing on the growing importance of patient preference and adherence throughout the therapeutic continuum. Patient satisfaction, acceptability, quality of life, compliance, persistence and their role in developing new therapeutic modalities and compounds to optimize clinical outcomes for existing disease states are major areas of interest for the journal. This journal has been accepted for indexing on PubMed Central. The manuscript management system is completely online and includes a very quick and fair peer-review system, which is all easy to use. Visit http:// www.dovepress.com/testimonials.php to read real quotes from published authors. 